\title{
Prehospital Intervals and In-Hospital Trauma Mortality: A Retrospective Study from a Level I Trauma Center
}

\author{
Hassan Al-Thani, MD $;^{1}$ Ahammed Mekkodathil, MPH; ${ }^{1}$ Attila J. Hertelendy, PhD; ${ }^{2} \odot$ \\ Tim Frazier, PhD $;^{3}$ Gregory R. Ciottone, $\mathrm{MD} ;{ }^{4}$ Ayman El-Menyar, $\mathrm{MD}^{1,5}$ (
}

1. Department of Surgery, Trauma and Vascular Surgery, Hamad General Hospital, Doha, Qatar

2. Department of Decision Sciences and Business Analytics, College of Business, Florida International University, Miami, USA

3. Emergency and Disaster Management program, Georgetown University, Washington, DC, USA

4. Department of Emergency Medicine, Beth Israel Deaconess Medical Center, Boston, Massachusetts USA

5. Department of Clinical Medicine, Weill Cornell Medical College, Doha, Qatar

Correspondence:

Ayman El-Menyar, MD, FRCP, FACC, FESC

Associate Professor Weill Cornell Medical College

Consultant Clinical Research, Trauma Surgery

Hamad General Hospital, Doha, Qatar

E-mail: aymanco65@yahoo.com

Conflicts of interest: none

Keywords: mortality; prehospital; trauma; triage

Abbreviations:

ACS: American College of Surgeons

EMS: Emergency Medical Services

ESRI: Environmental Systems Research Institute HEMS: helicopter Emergency Medical Services HGH: Hamad General Hospital

HMC: Hamad Medical Corporation

HMCAS: Hamad Medical Corporation

Ambulance Service

HTC: Hamad Trauma Center

ICU: intensive care unit

ISS: Injury Severity Score

MOI: Ministry of Interior

NCC: National Command Center

NTDB: National Trauma Databank

OST: on-scene time

RTI: road traffic injury

\section{Abstract}

Background: The increase in mortality and total prehospital time (TPT) seen in Qatar appear to be realistic. However, existing reports on the influence of TPT on mortality in trauma patients are conflicting. This study aimed to explore the impact of prehospital time on the in-hospital outcomes.

Methods: A retrospective analysis of data on patients transferred alive by Emergency Medical Services (EMS) and admitted to Hamad Trauma Center (HTC) of Hamad General Hospital (HGH; Doha, Qatar) from June 2017 through May 2018 was conducted. This study was centered on the National Trauma Registry database. Patients were categorized based on the trauma triage activation and prehospital intervals, and comparative analysis was performed. Results: A total of 1,455 patients were included, of which nearly one-quarter of patients required urgent and life-saving care at a trauma center (T1 activations). The overall TPT was 70 minutes and the on-scene time (OST) was 24 minutes. When compared to T2 activations, T1 patients were more likely to have been involved in road traffic injuries (RTIs); experienced head and chest injuries; presented with higher Injury Severity Score (ISS: median $=22)$; and had prolonged OST (27 minutes) and reduced TPT (65 minutes; $\mathrm{P}=.001$ ). Prolonged OST was found to be associated with higher mortality in T1 patients, whereas TPT was not associated.

Conclusions: In-hospital mortality was independent of TPT but associated with longer OST in severely injured patients. The survival benefit may extend beyond the golden hour and may depend on the injury characteristics, prehospital, and in-hospital settings.

Al-Thani H, Mekkodathil A, Hertelendy AJ, Frazier T, Ciottone GR, El-Menyar A. Prehospital intervals and in-hospital trauma mortality: a retrospective study from a Level I trauma center. Prehosp Disaster Med. 2020;35(5):508-515.

\section{Introduction}

Trauma is the leading cause of death and disabilities for individuals up to the age of 45 years world-wide. ${ }^{1,2}$ High-quality prehospital care remains a vital part of the trauma system which significantly impacts the survivability of severely injured patients. Trauma is recognized as a time-dependent health condition among trauma surgeons and Emergency Medical Service (EMS) providers. It is widely accepted in trauma that morbidity and mortality improve if injured patients receive definitive care within 60 minutes (golden hour) of time of injury, after which both increase significantly. ${ }^{3}$ However, the debate continues on "whether to rely mainly on the speed of response and transport (scoop and run) or to spend time at the scene to initiate primary treatment and stabilize the patient before transport (stay and play)." ${ }^{3-6}$

T1: triage- 1
T2: triage- 2
TPT: total prehospital time
TQIP: Trauma Quality Improvement Program

Received: March 2, 2020

Revised: March 31, 2020

Accepted: April 8, 2020
doi:10.1017/S1049023X20000904

(C) World Association for Disaster and Emergency Medicine 2020. This is an Open Access article, distributed under the terms of the Creative Commons Attribution licence (http:// creativecommons.org/licenses/by/4.0/), which permits unrestricted re-use, distribution, and reproduction in any medium, provided the original work is properly cited. 
Previous studies suggest that the decision making on rapid transfer of injured patients to definitive care versus taking time for stabilization of patients on-scene is influenced by several factors. In some instances, field stabilization is more beneficial, whereas speed of transfer to a definitive care facility is crucial in cases with more critical time-limited issues. ${ }^{7,8}$ For example, the first minutes of care for a patient with a thoracic gunshot wound and left ventricular injury are regarded as the "golden five minutes" because of the emergent requirement for life-saving treatment. On the other hand, it may be a "golden" day or two for a patient who was a victim of a motor vehicle accident and isolated tibia fracture. In reality, the data remain inconclusive as they are influenced by the experience and abilities of prehospital personnel, which can vary dramatically by geographic location and between different trauma systems. ${ }^{9-15}$ However, prehospital personnel in the field are an integral part of the care process, and the key treatment principles in prehospital care should remain the same.

Most trauma systems have specific protocols based on physiological parameters, anatomical location, and injury mechanism criteria to direct a patient to the correct facility. Prehospital trauma triage should ideally result in transport of the right patient to the right facility so that under-triage or overt-triage can be minimized. A systematic review on the effectiveness of prehospital trauma triage systems revealed that a significant number of the severely injured patients were not transported to the appropriate level of trauma center. ${ }^{16}$ The present study aims to explore the influence of prehospital times on mortality among patients with different trauma triage criteria.

\section{Methods}

A retrospective study of all trauma patients transferred by EMS and admitted to the Hamad Trauma Center (HTC) of Hamad General Hospital (HGH; Doha, Qatar) was conducted. The study was based on National Trauma Registry data from June 1, 2017 through May 31, 2018. All trauma patients with total prehospital time (TPT) recorded in the Trauma Registry were included in the final analysis. Patients brought to the hospital dead-on-arrival were excluded. The TPT in this study was defined as the duration between EMS notification time and hospital arrival time. Response time was the difference between EMS notification time and arrival at the scene. On-scene time (OST) was the time duration between arrival and departure of EMS from the scene.

The HGH is the only Level I trauma center in Qatar that receives all moderate to severe trauma patients, and is equipped with well-established services. Trauma registry data for the $\mathrm{HGH}$ is nationally collected and captures all patient-care events, including the prehospital and in-hospital course of patients. In 2017, the HGH Trauma Registry was officially launched as the Qatar National Trauma Registry, which contributes to the National Trauma Databank (NTDB) of the American College of Surgeons (ACS; Chicago, Illinois USA) Committee on Trauma, the largest international trauma registry database ever assembled. The HGH Trauma Registry has been validated internationally and locally. The international validation includes the quarterly reporting to the NTDB and the ACS Trauma Quality Improvement Program (TQIP). The HGH Trauma Registry is a part of the Qatar National Trauma Registry that has regular auditing as well as the regular departmental checking for accuracy and minimizing the rate of missing data. Data definitions are updated based on the International Classification of Diseases, 10th Revision, Clinical Modification (ICD-10-CM) code and TQIP dictionary.

The present study collected demographic information of patients, mechanisms of injury, injured body regions, prehospital intervals, comorbidities, Injury Severity Scores (ISS), interventions, details of the hospital course, and mortality. Initially, data on all patients transferred alive to the HTC were retrieved from the Trauma Registry over the study duration. The data on patients lacking recorded TPT or transferred from other hospitals and not admitted at HTC were excluded (Figure 1). Patients transferred from the Emergency Resuscitation Unit (ERU) of $\mathrm{HGH}$ to the Trauma Resuscitation Unit (TRU) were included. Patients included in the final analysis were classified into groups based on triage at the trauma center, such as triage-1 (T1) and triage2 (T2) for comparative analysis (Table 1). Further comparison between patients who died versus those who survived was performed among the patients with $\mathrm{T} 1$ activation (mortality in T2 group was very low; Table 2). In addition, T1 patients who died and who survived were further analyzed based on different categories of TPT and OST (Table 3). Triage takes into account mechanism of injury, presenting vital signs, prehospital clinical course, and other medical conditions. Assignment of T1 or priority-1 (P1) represents patients who required immediate life-saving interventions, whereas $\mathrm{T} 2$ or priority-2 (P2) patients required emergent or urgent intervention within two to four hours. Triage-3 (T3) or priority-3 (P3) patients required medical treatment that could be safely delayed. ${ }^{17}$ In Qatar, the National Command Center (NCC; Doha, Qatar) was established to manage local and national emergencies by coordinating emergency operations, ensuring rapid and efficient inter-agency responses. ${ }^{18}$ The NCC operates with the Ministry of Interior (MOI; Doha, Qatar), Emergency Service Center, Internal Security Forces, and Hamad Medical Corporation (HMC; Doha, Qatar). The HMC is the operator of the national Ambulance Services (HMCAS). Emergency calls are triaged by a MOI dispatcher to determine whether the call is related to fire, medical, or police. This initial information is captured in the computer-assisted dispatch system known as "Najem" (the Arabic acronym for Unified Geospatial Infrastructure). ${ }^{18,19}$ This bilingual (Arabic/English) web-based application was developed by the Mannai Corporation in Qatar, along with the Environmental Systems Research Institute (ESRI; Cairo, Egypt) Northeast Africa, in consultation with the national security team of ESRI. Najem integrates all NCC functions into a single system and seamlessly interfaces with other systems when needed. Incident details and location are provided by the Najem dispatching application, which also provides the location of responding vehicles and their availability status. Since implementation, the emergency response time per incident has been significantly reduced, and all stakeholders benefit from the geospatial-based common operational picture that allows an immediate connection between incidents, units, critical infrastructures, priority assets, and other critical information. ${ }^{18}$ The HMCAS follows a "hub and spoke model" of deployment, in which the hub is comprised of supervisory officers and other administrative and support functions, and the spokes are small standby ambulance stations positioned in strategic areas across Qatar. Presently, the distribution model of HMCAS divides Qatar into six hubs, each with five to seven spoke stations.

\section{Data Analysis}

Data were presented as proportions and $95 \%$ confidence interval (CI), mean (standard deviation [SD]), or median with interquartile 


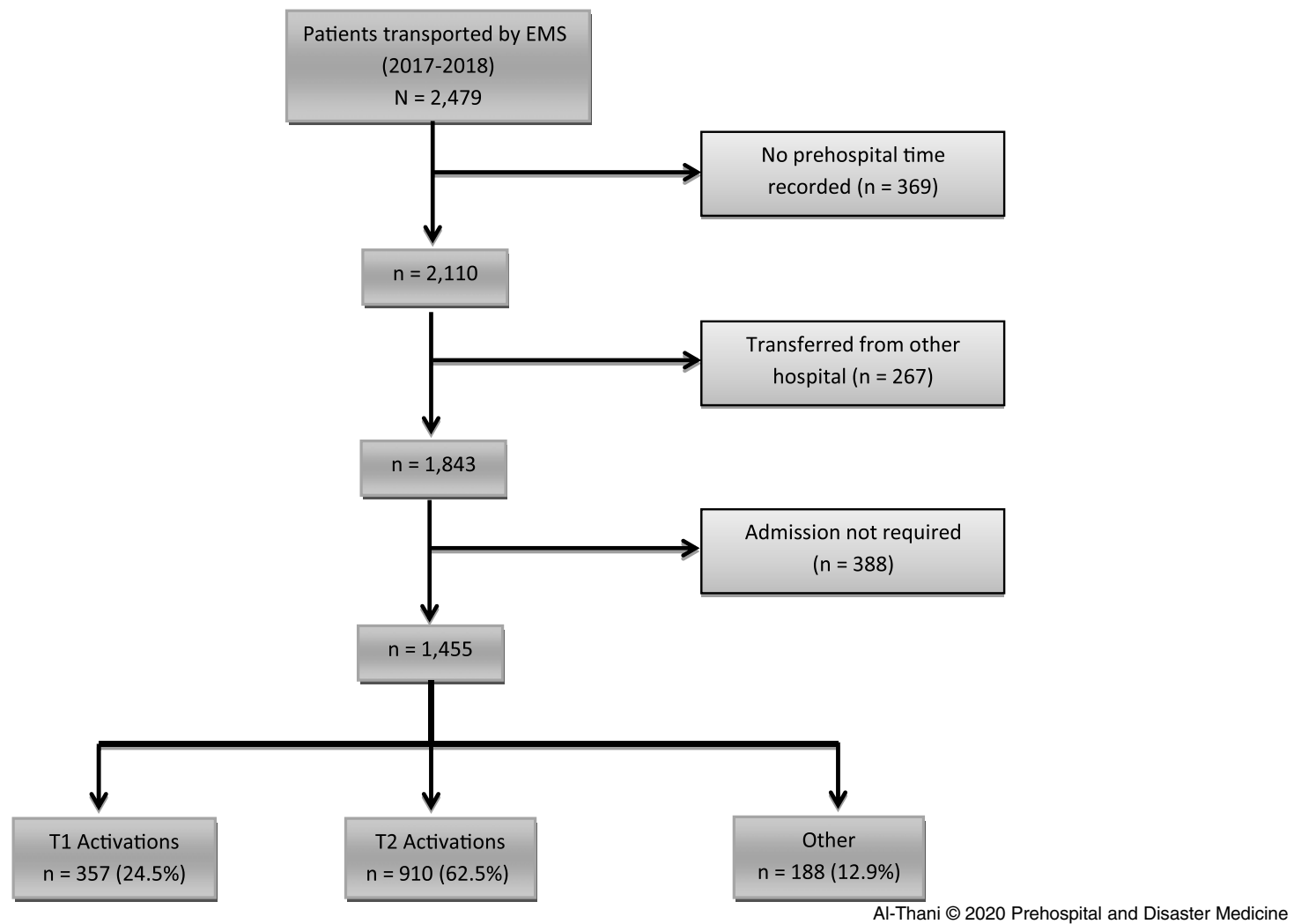

Figure 1. Flow Chart of Patients Included in the Study Based on Inclusion/Exclusion Criteria and Level of Trauma Activations. Note: T1 patients need immediate care whereas T2 patients require intermediate or urgent care within two to four hours. Abbreviations: EMS, Emergency Medical Services; T1, triage-1; T2, triage-2.

range (IQR), as appropriate. The chi-square test was used to compare proportions between the groups at a significant level of $\mathrm{P}$ value $<.05$. Means of quantitative variables were compared using student t-test and the difference was considered as significant at $\mathrm{P}$ value level <.05. Medians were compared using non-parametric tests. Data analysis was carried out using the Statistical Package for Social Sciences version 21 (SPSS Inc.; Chicago, Illinois USA). Ethical approval for this study was obtained (MRC-0118-432) from Institutional Review Board at HMC, Doha, Qatar with a waiver of informed consent.

\section{Results}

In the study duration, 2,479 patients in the Qatar National Trauma Registry database were screened for inclusion, and a total of 1,455 patients were retained in the final analysis. The main reasons for exclusions were patients who did not require trauma admission $(n=388)$, prehospital time was not recorded $(n=369)$, and patients who were transferred from other hospitals $(n=267$; Figure 1). Of those 1,455 patients, 357 (24.5\%) were in T1 activation group and $910(62.5 \%)$ were in T2 activation group. The remaining 188 (12.9\%) patients lacking triage criteria information were categorized as "other." Figure 2 shows the locations across the country from where patients were transported to the HGH by EMS over the study duration.

Table 1 shows the patients demographics, injury characteristics, prehospital intervals, in-hospital course, and outcomes of all T1 and T2 patients. The mean patient age was 32 years, and this was comparable among both T1 and T2 groups. The majority of victims were male, making up a significantly higher proportion of the $\mathrm{T} 1$ group $(\mathrm{P}=.001)$. Road traffic injuries (RTIs) and falls were most common mechanisms of injuries in all patient groups. However, RTI was proportionately higher in the T1 group, whereas falls were more frequent in the $\mathrm{T} 2$ group $(\mathrm{P}=.001)$. Head, chest, and lower extremity injuries were more common in the T1 group when compared to T2 $(\mathrm{P}=.001)$. Polytrauma was more common among the $\mathrm{T} 1$ group with significantly higher ISS (median $=22$ ), with intubation, chest tube insertion, cricothyrotomy, and exploratory laparotomy performed more commonly than when compared to $\mathrm{T} 2(\mathrm{P}=.001)$.

Notably, 398 (27.4\%) of patients were taken to the operating room within 24 hours of admission, and $59.5 \%$ of these patients were T2 patients while $36.9 \%$ were $\mathrm{T} 1$ patients. Massive transfusion protocol was activated in $80(5.5 \%)$ patients, and almost all were in the T1 group $(\mathrm{n}=78 ; 97.5 \%)$. Of the patients in groups other than T1 or T2 ( $\mathrm{n}=188,12.9 \%)$, more were injured following RTIs $(\mathrm{n}=112$; $59.5 \%)$ and experienced mostly head (30.1\%) and chest $(24.8 \%)$ injuries. The median ISS score among this group was nine (IQR 4-12).

Of the total 1,455 patients, $493(33.8 \%)$ were transported to the hospital within 60 minutes and $657(45.2 \%)$ had OST $\leq 20$ minutes. Of the $357 \mathrm{~T} 1$ patients, 147 (41.2\%) were transported to the hospital within 60 minutes and the OST was $\leq 20$ minutes in 116 (32.5\%). The overall median OST was 24 minutes and was higher in T1 compared to T2 $(27$ minutes versus 20 minutes; $\mathrm{P}=.001)$. The overall TPT was 70 minutes and was less in T1 compared to T2 (65 minutes versus 71 minutes; $\mathrm{P}=.001$ ). The 


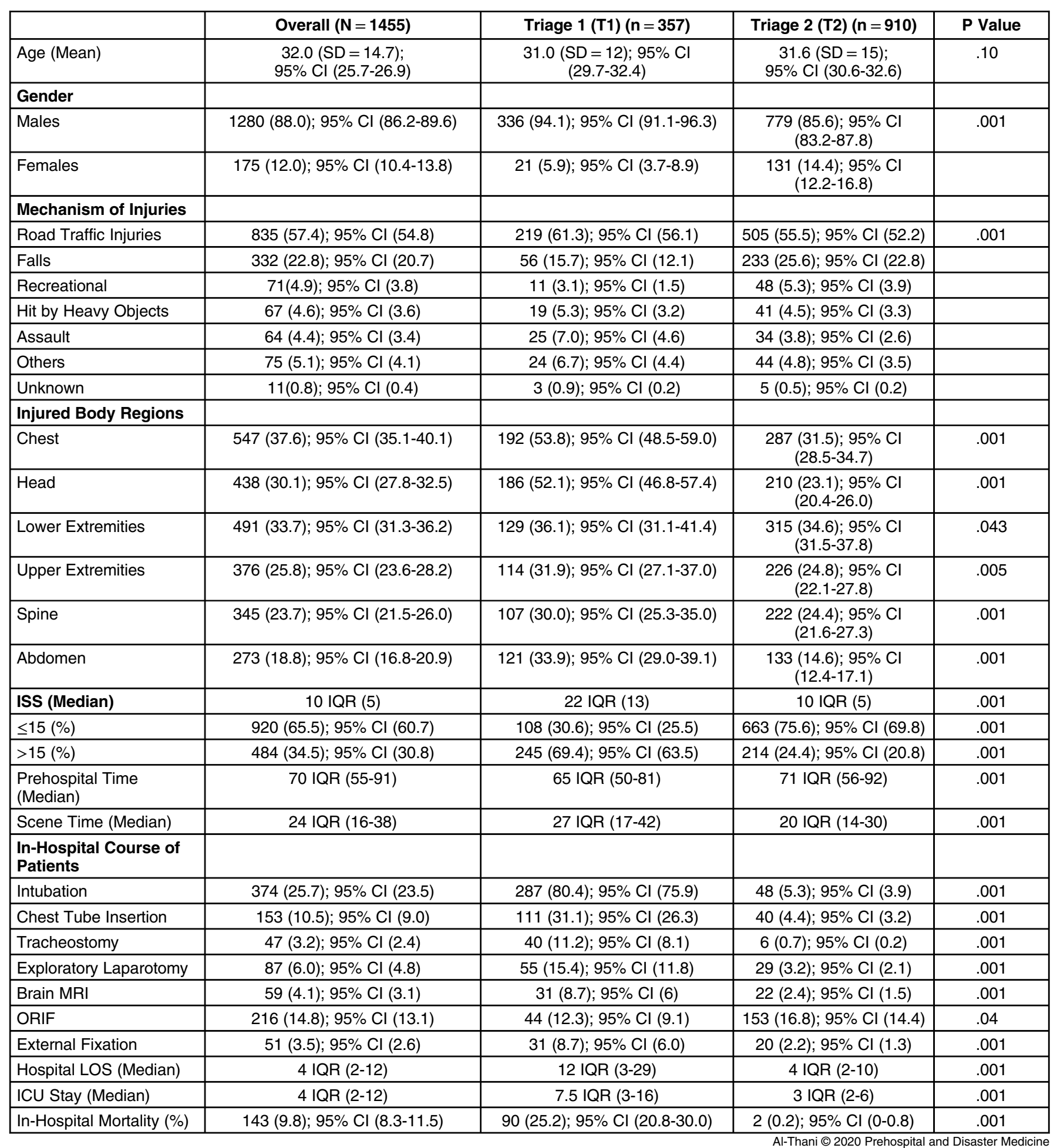

Table 1. Characteristics of Patients Transported by Emergency Medical Services in Qatar by Trauma Triage Criteria

Note: Data expressed as numbers, percentages or mean (SD) with $95 \%$ confidence interval (CI), or median with interquartile range (IQR).

Abbreviations: ICU, intensive care unit; ISS, Injury Severity Score; LOS, length of stay; MRI, magnetic resonance imaging; ORIF, open reduction internal fixation.

median duration of intensive care unit (ICU) and hospital stays were significantly higher in $\mathrm{T} 2$. In addition, the mortality rate was significantly higher in the T1 group when compared to the T2 group (25.2\% versus $0.2 \% ; \mathrm{P}=.001)$.
Of the patients who died, more were RTI victims (76.7\%) and had a significantly higher proportion of head (67.8\%) or chest (61.1\%) injuries, along with severe polytrauma as characterized by high ISS (median $=30$; Table 2 ). These patients were more 


\begin{tabular}{|c|c|c|c|}
\hline & Survival $(n=267)$ & Mortality $(n=90)$ & P Value \\
\hline Age & $30.5(\mathrm{SD}=12.0) ; 95 \% \mathrm{Cl}(29.1-32.0)$ & $33.5(\mathrm{SD}=14.2) ; 95 \% \mathrm{Cl}(29.6-37.4)$ & .11 \\
\hline Males & 248 (92.9); 95\% Cl (89.1-95.7) & 88 (97.8); 95\% Cl (92.2-99.7) & .08 \\
\hline Road Traffic Injuries & 150 (56.2); $95 \% \mathrm{Cl}(50.0-62.2)$ & 69 (76.7); 95\% Cl (66.6-84.9) & .002 \\
\hline Falls & 45 (16.9); 95\% Cl (12.6-21.9) & 11 (12.2); 95\% Cl (6.3-20.8) & \\
\hline Hit of Heavy Objects & $16(6.0) ; 95 \% \mathrm{Cl}(3.5-9.5)$ & 3 (3.3); $95 \% \mathrm{Cl}(0.7-9.4)$ & \\
\hline \multicolumn{4}{|l|}{ Injured Body Regions } \\
\hline Chest & 56 (21.0); 95\% Cl (16.2-26.4) & 55 (61.1); $95 \% \mathrm{Cl}(50.3-71.2)$ & .001 \\
\hline Head & 125 (46.8); 95\% Cl (40.7-53.0) & 61 (67.8); 95\% Cl (57.1-77.2) & .001 \\
\hline Lower Extremities & 95 (35.6); $95 \% \mathrm{Cl}(29.8-41.6)$ & 34 (37.8); 95\% Cl (27.8-48.6) & .70 \\
\hline Upper Extremities & 86 (32.2); 95\% Cl (26.6-38.2) & 28 (31.1); 95\% Cl (21.8-41.7) & .84 \\
\hline Scene Time (Median) & 26 IQR (15-40) & 33 IQR $(22-47)$ & .03 \\
\hline \multicolumn{4}{|l|}{ In-Hospital Course } \\
\hline Intubation & 197 (73.8); $95 \% \mathrm{Cl}(68.1)$ & 90 (100.0); $95 \% \mathrm{Cl}(96.0)$ & .001 \\
\hline Chest Tube Insertion & 56 (21.0); 95\% Cl (16.2) & 55 (61.1); $95 \% \mathrm{Cl}(50.3)$ & .001 \\
\hline Tracheostomy & 37 (13.9); 95\% Cl (9.9) & $3(3.3) ; 95 \% \mathrm{Cl}(0.7)$ & .006 \\
\hline Exploratory Laparotomy & 39 (14.6); $95 \% \mathrm{Cl}(10.6)$ & 16 (17.8); $95 \% \mathrm{Cl}(10.3)$ & .47 \\
\hline Hospital LOS (Median) & 21 IQR (3-27) & 9 IQR (8-45) & .001 \\
\hline ICU Stay (Median) & 8 IQR (3-17) & 5 IQR (2-14) & .53 \\
\hline
\end{tabular}

Table 2. Comparative Analysis of Survival versus Mortality in Patients with Trauma Triage-1 Criteria (T1)

Note: Data expressed as numbers, percentages in brackets, or mean (SD) with confidence interval (CI), or median with interquartile range (IQR) in bracket.

Abbreviations: ICU, intensive care unit; ISS, Injury Severity Score; LOS, length of stay.

likely to undergo intubation, chest tube insertion, or cricothyrotomy. Although the OST was longer for patients who died $(\mathrm{P}=.03)$, there was no significant difference in TPT between survival and mortality groups. Predictably, hospital stay was longer among the survived patients $(\mathrm{P}=.001)$, but the ICU duration was comparable $(\mathrm{P}=.53)$. The comparative analysis revealed that T1 patients had an increasing trend in mortality with increasing TPT and OST; however, it was statistically insignificant (Table 3).

\section{Discussion}

This study demonstrates that approximately $25 \%$ of patients transported by EMS to the Level I trauma center in Qatar had injuries that required immediate life-saving interventions, resulting in T1 activation. Although the total study population on average had prolonged TPT (median $=70$ minutes) exceeding the golden hour of 60 minutes in $69 \%$ of the patients, T1 patients had shorter TPT but longer OST. The longer OST reflects the severity of injury and time spent for immediate life-saving interventions at the scene; however, $63 \%$ of the total in-hospital, all-cause mortality occurred in T1 patients. Results suggest that the in-hospital mortality was independent of TPT but associated with OST (Table 2). Significant differences in injury characteristics of T1 and T2 patient groups in this study demonstrated the efficiency of the existing trauma triage system in Qatar.

In contrast to the present study, a recent study based on two French trauma registries demonstrated a linear association between
TPT and in-hospital all-cause mortality, with mortality rising by eight percent for each 10-minute increase. ${ }^{20}$ The prehospital system in the French study was physician-staffed, while critical care paramedics and Emergency Medical Technicians are involved in EMS in Qatar. Gonzalez, et al conducted a study on motor vehicle crashes in rural settings and demonstrated that increased TPT was associated with higher mortality. ${ }^{21}$ The study was based on data collected from EMS Patient Care Reports and police crash reports in urban settings. ${ }^{21}$

Another study based on data from a large number of EMS agencies and sites across North America could not demonstrate the relationship between prehospital intervals and survival. ${ }^{22}$ This finding was continual across subgroups by country, age, injury type, severe physiologic derangement, or level of first responding EMS provider. ${ }^{22}$ Similarly, Dinh, et al found that there was no survival benefit in patient arrival at hospital within 60 minutes of injury time (golden hour) in patients with severe head injuries characterized by abbreviated injury scale greater than three. ${ }^{23}$ On the other hand, a two-hour cut-off time in reaching the hospital was shown to have some benefits in survival. ${ }^{23}$ Ringburg, et al also showed that the combined ground and helicopter EMS (HEMS) assistance at an injury scene was associated with longer OST. ${ }^{24}$ No influence of longer OST on mortality was demonstrated when severity of injury and patient characteristics were adjusted. ${ }^{24} \mathrm{~A}$ large retrospective study based on Pennsylvania (USA) trauma registry data, which included 164,471 patients over a 14-year duration (2000-2013), 


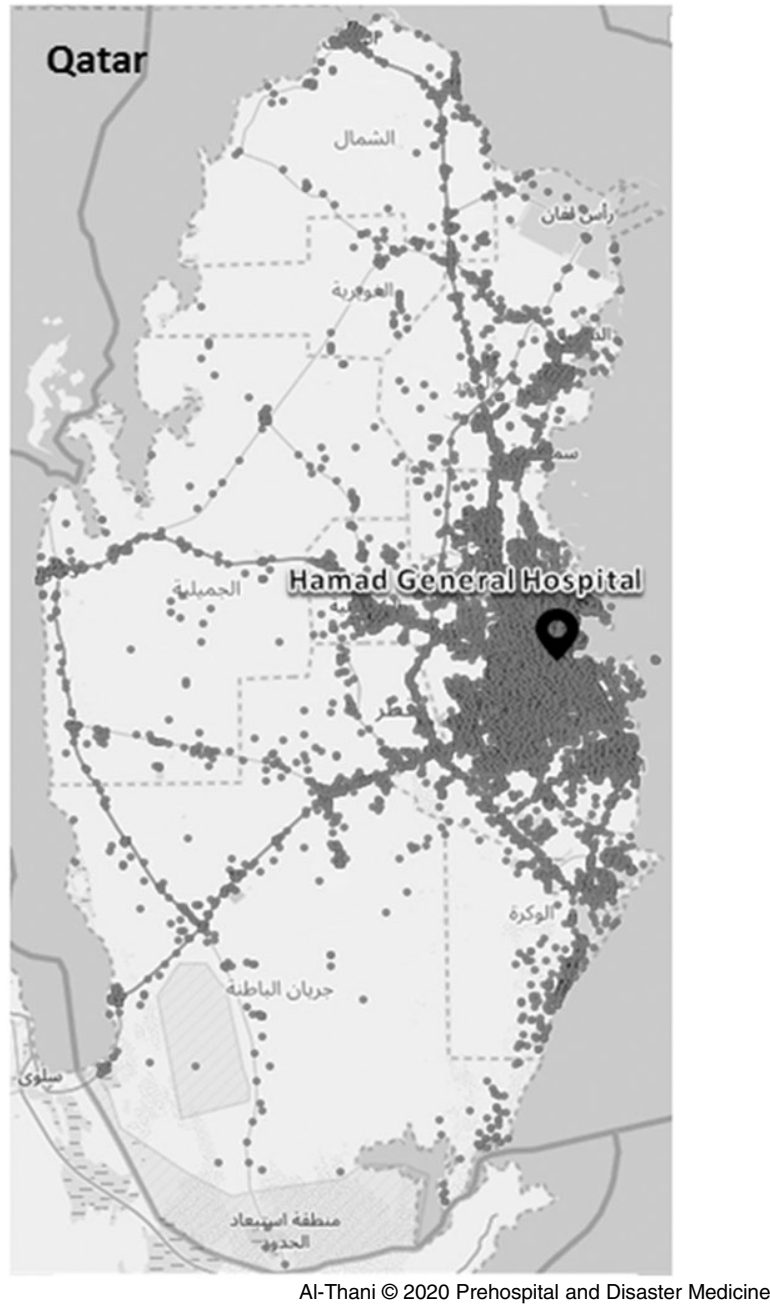

Figure 2. Map Showing the Locations Across the Country from where Patients Transported to Hamad General Hospital.

revealed that prolonged OST was associated with increased mortality. ${ }^{25}$ Prehospital intubation and extrication partially facilitated the association between prolonged OST and mortality. Patients with hypotension, flail chest, and penetrating injury were time-sensitive. While adjusting the response and transport time, patients with severe head injury intubated by HEMS providers did not show any association between prehospital intubation and increased mortality. ${ }^{25}$

A previous study in Qatar showed that patients transported by HEMS had 2.5-fold higher mortality when compared to the patients transported by the ground ambulance. These patients had a greater ISS, more traumatic brain injury, and increased frequency of on-scene intubation. ${ }^{26}$ However, this study did not explore the impact of prehospital intervals on patient outcomes. Kidher, et al conducted a retrospective analysis of 688 HEMS transfers with severe thoracic trauma (mean ISS $=35$ ) which revealed that TPT $<65$ minutes was associated with lower mortality. ${ }^{27}$
Thoracic trauma victims usually have high ISS with $38 \%$ of this patient population experiencing thoracic trauma and a mortality rate of $21 \%$. In addition, $30 \%$ of these patients had head injuries and $21 \%$ had head injuries with an ISS score level $>15$. Only one out of three patients were transported to the trauma center within the golden hour, while $92 \%$ were transported within two hours. The median TPT for severely injured patients with head injuries was 67 minutes and OST was 30 minutes. Based on these data, this study concludes that the survival benefit may extend beyond the golden hour and depend on the injury characteristics, as well as prehospital and in-hospital settings. Findings in this study are consistent with previous studies which have reported lack of association between TPT and mortality in patients with traumatic injuries.

Comparative analysis based on the triage activation levels in this study provided an opportunity to assess the accuracy of the established triage system in Qatar. The mortality rate among the T1 group was predictably higher, even though more time was spent on life-saving interventions in prehospital and in-hospital settings. On the other hand, the mortality rate in patient groups other than $\mathrm{T} 1$ or T2 was higher; 51 died out of 188 patients (27.1\%). No triage criteria were recorded for this group of patients, and they were transferred from an emergency department unit to a trauma room unit. Some of these patients might have later been upgraded to $\mathrm{T} 1$ or T2; however, this information was lacking because of the retrospective design of the study. The majority of these patients were RTI victims with head or chest injuries. They had low ISS when compared to T1 patients, but were close to the median ISS of the T2 patients. Twenty-five patients in this group had ISS $>15$ and 15 of them died in the hospital.

The group of patients with no triage criteria can be further investigated to assess the possibility of under-triage. However, severe injuries in this group constitute less than two percent of the total study population and may not affect the results of the study. A systematic review on the association between transfer status and outcomes for patients revealed that transfer status (ie, transfer versus direct) was not associated with in-hospital mortality. ${ }^{28}$ Conversely, triaging severely injured patients to non-trauma facilities which are incapable of providing definitive care is associated with increased mortality. ${ }^{29}$ Initial stabilization attempts at these facilities may be harmful. Therefore, "scoop and run" to the trauma center may be much better when compared to "stay and play" at the local hospital.

\section{Limitations}

The retrospective nature of this study is a limitation. Missing data and selection bias cannot be ignored; however, data were extracted from a robust and validated trauma registry. Factors that affect each component of the OST (ie, arrival, scene management, and departure) need further analysis and interpretation.

\section{Conclusions}

This analysis suggests that in-hospital mortality is independent of TPT or OST. The survival benefit may extend beyond the golden hour and depends on injury characteristics as well as prehospital/inhospital settings. Future prospective studies are warranted to explore whether improved prehospital care outweighs potential harm associated with patient transfer to hospital. 


\section{References}

1. World Health Organization. Injuries and violence: the facts 2014. https://apps.who.int/ iris/bitstream/handle/10665/149798/9789241508018_eng.pdf;jsessionid=9CF9DC3A7 C1835C12709966F43C295AF?sequence=1. Accessed February 2020.

2. Haagsma JA, Graetz N, Bolliger I, et al. The global burden of injury: incidence, mortality, disability-adjusted life years, and time trends from the Global Burden of Disease study 2013. Inj Prev. 2016;22(1):3-18.

3. Clark DE. RA Cowley, the "Golden Hour," the "Momentary Pause," and the "Third Space." Am Surg. 2017;83(12):1401-1406.

4. Haas B, Nathens AB. Pro/con debate: is the scoop and run approach the best approach to trauma services organization? Crit Care. 2008;12(5):224.

5. Wyen H, Lefering R, Maegele M, et al; TraumaRegister DGU. The golden hour of shock-how time is running out: prehospital time intervals in Germany: a multivariate analysis of 15,103 patients from the TraumaRegister DGU(R). Emerg Med J. 2013;30(12):1048-1055.

6. Meizoso JP, Valle EJ, Allen CJ, et al. Decreased mortality after prehospital interventions in severely injured trauma patients. J Trauma Acute Care Surg. 2015;79(2): 227-231.

7. Smith RM, Conn AK. Prehospital care - scoop and run or stay and play? Injury. 2009;40(Suppl 4):S23-26.

8. Harmsen AM, Giannakopoulos GF, Moerbeek PR, Jansma EP, Bonjer HJ, Bloemers FW. The influence of prehospital time on trauma patients' outcome: a systematic review. Injury. 2015;46(4):602-609.

9. Quinn LM, French J, Mackenzie R. Doctors and prehospital on-scene times: effect is still debatable. Emerg Med J. 2007;24(7):521; author reply 521.

10. Dissmann PD, Le Clerc S. The experience of Teesside helicopter emergency services: doctors do not prolong prehospital on-scene times. Emerg Med J. 2007;24(1):59-62

11. Feero S, Hedges JR, Simmons E, et al. Does out-of-hospital time affect trauma survival? Am J Emerg Med. 1995;13(2):133-135.

12. Sampalis JS, Lavoie A, Salas M, et al. Determinants of on-scene time in injured patients treated by physicians at the site. Prehosp Disaster Med. 1994;9(3):178-188.

13. Garner A, Rashford S, Lee A, et al. Addition of physicians to paramedic helicopter services decreases blunt trauma mortality. Aust NZ J Surg. 1999;69(10):679-701.

14. Iirola TT, Laaksonen MI, Vahlberg TJ, et al. Effect of physician-staffed helicopter emergency medical service on blunt trauma patient survival and prehospital care. Eur J Emerg Med. 2006;13(6):335-339.

15. Sampalis JS, Lavoie A, Williams JI, et al. Impact of on-site care, prehospital time, and level of in-hospital care on survival in severely injured patients. J Trauma. 1993;34(2):252-261.
16. van Rein EAJ, van der Sluijs R, Houwert RM, et al. Effectiveness of prehospital trauma triage systems in selecting severely injured patients: is comparative analysis possible? Am J Emerg Med. 2018;36(6):1060-1069.

17. Kilner T. Triage decisions of prehospital emergency health care providers, using a multiple casualty scenario paper exercise. Emerg Med J. 2002;19(4):348-353.

18. Ebrahim AH, Osama $\mathrm{M}$. Qatar enters a new era of emergency response and proactive security. Esri 2014. https://www.esri.com/ /media/Files/Pdfs/library/brochures/pdfs/ qatar-enters-a-new-era.pdf. Accessed February 2020.

19. Wilson P, Alinier G, Reimann, T, Morris, B. Influential factors on urban and rural response times for emergency ambulances in Qatar. MJEM. 2018;26:8-13.

20. Gauss T, Ageron FX, Devaud ML, et al; French Trauma Research Initiative. Association of prehospital time to in-hospital trauma mortality in a physician-staffed emergency medicine system. JAMA Surg. 2019;154(12):1117-1124.

21. Gonzalez RP, Cummings GR, Phelan HA, Mulekar MS, Rodning CB. Does increased emergency medical services prehospital time affect patient mortality in rural motor vehicle crashes? A statewide analysis. Am J Surg. 2009;197(1):30-34.

22. Newgard CD, Schmicker RH, Hedges JR, et al; Resuscitation Outcomes Consortium Investigators. Emergency medical services intervals and survival in trauma: assessment of the "golden hour" in a North American prospective cohort. Ann Emerg Med. 2010;55(3):235-246.

23. Dinh MM, Bein K, Roncal S, Byrne CM, Petchell J, Brennan J. Redefining the golden hour for severe head injury in an urban setting: the effect of prehospital arrival times on patient outcomes. Injury. 2013;44(5):606-610.

24. Ringburg AN, Spanjersberg WR, Frankema SP, Steyerberg EW, Patka P, Schipper IB. Helicopter emergency medical services (HEMS): impact on on-scene times. J Trauma. 2007;63(2):258-262.

25. Brown JB, Rosengart MR, Forsythe RM, et al. Not all prehospital time is equal: influence of scene time on mortality. J Trauma Acute Care Surg. 2016;81(1):93-100.

26. Al-Thani H, El-Menyar A, Pillay Y, Mollazehi M, Mekkodathil A, Consunji R. Hospital mortality based on the mode of Emergency Medical Services transportation. Air Med J. 2017;36(4):188-192.

27. Kidher E, Krasopoulos G, Coats T, et al. The effect of prehospital time related variables on mortality following severe thoracic trauma. Injury. 2012;43(9):1386-1392.

28. Hill AD, Fowler RA, Nathens AB. Impact of interhospital transfer on outcomes for trauma patients: a systematic review. J Trauma. 2011;71(6):1885-1901.

29. Nirula R, Maier R, Moore E, Sperry J, Gentilello L. Scoop and run to the trauma center or stay and play at the local hospital: hospital transfers effect on mortality. J Trauma. 2010;69(3):595-601. 


\begin{tabular}{|c|c|c|c|c|c|c|c|c|c|}
\hline $\begin{array}{l}\text { TPT } \\
\text { minutes }\end{array}$ & Total No. (\%) & Survival & Mortality & P Value & OST minutes & Total No. (\%) & Survival & Mortality & P Value \\
\hline $0-29$ & $\begin{array}{c}14 \text { (3.9); } 95 \% \mathrm{Cl} \\
(2.2-6.5)\end{array}$ & $\begin{array}{c}11(4.1) ; 95 \% \mathrm{Cl} \\
(2.1-7.3)\end{array}$ & $\begin{array}{c}3 \text { (3.3); } 95 \% \mathrm{Cl} \\
(7-9.4)\end{array}$ & \multirow[t]{6}{*}{.87} & $0-9$ & $\begin{array}{c}20 \text { (6.0); } 95 \% \mathrm{Cl} \\
(3.7-9.1)\end{array}$ & $\begin{array}{c}16(6.5) ; 95 \% \mathrm{Cl} \\
(3.7-10.3)\end{array}$ & $\begin{array}{c}4(4.7) ; 95 \% \mathrm{Cl} \\
(1.3-11.6)\end{array}$ & \multirow[t]{6}{*}{.12} \\
\hline $30-59$ & $\begin{array}{c}123 \text { (34.5); } 95 \% \mathrm{Cl} \\
(29.5-39.6) \\
\end{array}$ & $\begin{array}{c}94 \text { (35.2); } 95 \% \mathrm{Cl} \\
(29.5-41.3)\end{array}$ & $\begin{array}{c}29 \text { (32.2); } 95 \% \mathrm{Cl} \\
(22.8-42.9)\end{array}$ & & $10-19$ & $\begin{array}{c}84(25.1) ; 95 \% \mathrm{Cl} \\
(20.6-30.2) \\
\end{array}$ & $\begin{array}{c}70 \text { (28.2); } 95 \% \mathrm{Cl} \\
(22.7-34.3) \\
\end{array}$ & $\begin{array}{c}14(16.5) ; 95 \% \mathrm{Cl} \\
(9.3-26.1)\end{array}$ & \\
\hline $60-89$ & $\begin{array}{c}160(44.8) ; 95 \% \mathrm{Cl} \\
(39.6-50.1)\end{array}$ & $\begin{array}{c}116(43.4) ; 95 \% \mathrm{Cl} \\
(37.4-49.6)\end{array}$ & $\begin{array}{c}44 \text { (48.9); } 95 \% \mathrm{Cl} \\
(38.2-59.7)\end{array}$ & & $20-29$ & $\begin{array}{c}85 \text { (25.4); } 95 \% \mathrm{Cl} \\
(20.9-30.5)\end{array}$ & $\begin{array}{c}65(26.2) ; 95 \% \mathrm{Cl} \\
(20.8-32.1)\end{array}$ & $\begin{array}{c}20(23.5) ; 95 \% \mathrm{Cl} \\
(15.0-34.0)\end{array}$ & \\
\hline $90-119$ & $\begin{array}{c}43 \text { (12.0); } 95 \% \mathrm{Cl} \\
(8.9-15.9)\end{array}$ & $\begin{array}{c}34(12.7) ; 95 \% \mathrm{Cl} \\
(9-17.3)\end{array}$ & $\begin{array}{c}9 \text { (10.0); } 95 \% \mathrm{Cl} \\
(4.7-18.1)\end{array}$ & & $30-39$ & $\begin{array}{c}59 \text { (17.7); } 95 \% \mathrm{Cl} \\
(13.7-22.2) \\
\end{array}$ & $\begin{array}{c}41 \text { (16.5); } 95 \% \mathrm{Cl} \\
(12.1-21.8)\end{array}$ & $\begin{array}{c}18 \text { (21.2); } 95 \% \mathrm{Cl} \\
(13.1-31.4)\end{array}$ & \\
\hline $120-179$ & $\begin{array}{c}17 \text { (4.8); } 95 \% \mathrm{Cl} \\
(2.8-7.5) \\
\end{array}$ & $\begin{array}{c}12 \text { (4.5); } 95 \% \mathrm{Cl} \\
(2.3-7.7) \\
\end{array}$ & $\begin{array}{c}5 \text { (5.6); } 95 \% \mathrm{Cl} \\
(1.8-12.5)\end{array}$ & & $\geq 40$ & $\begin{array}{c}86(25.7) ; 95 \% \mathrm{Cl} \\
(21.1-30.8) \\
\end{array}$ & $\begin{array}{c}57 \text { (23.0); } 95 \% \mathrm{Cl} \\
(17.9-28.7) \\
\end{array}$ & $\begin{array}{c}29 \text { (34.1); } 95 \% \mathrm{Cl} \\
(24.2-45.2)\end{array}$ & \\
\hline Total & $357(100)$ & $267(100)$ & $90(100)$ & & Total & $334(100)$ & $248(100)$ & $85(100)$ & \\
\hline
\end{tabular}

Al-Thani $\odot 2020$ Prehospital and Disaster Medicin

Table 3. Comparative Analysis of Survival versus Mortality by Total Prehospital Time (TPT) and On-Scene Time (OST) in Patients with Trauma Triage-1 Criteria (T1) Note: Data expressed as numbers and percentages with $95 \%$ confidence interval (CI). 